\title{
Editorial
}

\section{International Journal of Project Management Special Issue on}

"Project Benefit Management"

Zwikael, O. (2016). Editorial - International Journal of Project Management special issue on "project benefit management". International Journal of Project Management, 34 (4), 734-735.

The project management literature and international standards have been preoccupied with delivering outputs (artifacts such as a bridge). Accordingly, project management methodologies and tools are focused on enhancing the efficiency of output delivery - on time, within budget and at specifications. While this approach is well-founded, a sole focus on efficient delivery of outputs does not support project effectiveness. Recently, a wider view of projects has emerged, which recognizes their role in the creation of strategic value (Shenhar and Dvir, 2007; Zwikael and Smyrk, 2015). Such a view accepts that organizations invest in projects with the specific objective of realizing identified target benefits.

Project benefits are "the flows of value that arise from a project" (Zwikael and Smyrk, 2012: 11). For example, a city council funds a project to reduce the number of accidents next to a school (through the construction of a bridge). The benefits associated with fewer accidents will flow into the future after completion of the bridge. Whereas numerous project management tools are available to the construction company in building the bridge, there is a gap in the literature regarding the role of the city council which (as the funding entity), is primarily concerned with ensuring that accident rates fall. To secure this result, the project scope may need to be expanded with additional activities such as road safety training for the kids and change of behavior monitoring.

Project benefit management is an emerging research area that emphasizes the strategic roles of projects in organizations, and describes the benefit management process within projects (e.g., Breese et al., 2015). Papers included in this Special Issue (summarized below) provide useful insights into the following core questions:

- What is the project benefit management process? 
- What theories are relevant for project benefit management?

- What are the implications of benefit management research on project governance, the concept of project success, and the project management tool kit?

In the first paper "Taking Stock of Project Value Creation: A Structured Literature Review with Future Directions for Research and Practice", Laursen and Svejvig provide a comprehensive literature review of project benefit management. Their findings highlight inconsistent terminology. Their review also identifies a number of theories relevant to this research area, including "Resource-based view", "Contingency theory", "Principal-agent theory", "Transactional cost theory" and Porter's "Value chain". They conclude that the project management literature rarely supports value creation for the funding organization. Their analysis highlights an important distinction between project management success and project success. While the former relates to efficient output delivery, the latter is concerned with benefit realization for the funding organization. Finally, the authors suggest four directions for future research in this area.

In the paper entitled "Benefits of Information System Projects: The Tale of Two Countries", Marnewick demonstrates the importance of a benefit management process in information system projects. The author concludes that information system projects do not contribute sufficiently to the implementation of organizational vision or strategy and that they should add benefit management practices to their remit to ensure they generate value. The author also argues that all projects should realize benefits in excess of the resources consumed and that benefit realization is not confined just to programs.

In "The Impact of Project Management (PM) and Benefits Management (BM) Practices on Project Success: Towards Developing a Project Benefits Governance Framework", Badewi provides empirical evidence that project management practices alone do not result in successful projects, and that a combination of project management and benefit management processes significantly improves projects' success rates. The author conceptualizes the project management process (focusing on outputs and led by the Project Manager) as parallel to the benefit management process (focusing on outcomes and led by the benefits owner-otherwise known as the Project Owner). 
Finally, in "Enhancing Project Benefit Realization through Integration of Line Managers as Project Benefit Managers", Dupont and Eskerod try to explore who is best situated to take on the role of the Project Owner. They provide a case from the Financial Sector in Europe that demonstrates how a Line (Functional) Manager can fill the Project Owner role effectively.

These papers have advanced research into project benefit management by suggesting a distinctive benefit management process that needs to be led by a Project Owner in parallel and in collaboration with the project management process, led by the Project Manager (see Figure 1). Benefits are first formulated during project initiation and included in the business case. Following the approval of the business case, the Funder(s) appoint a Project Owner, who becomes accountable for the realization of those target benefits. Achievement of this accountability requires the support of the Project Manager.

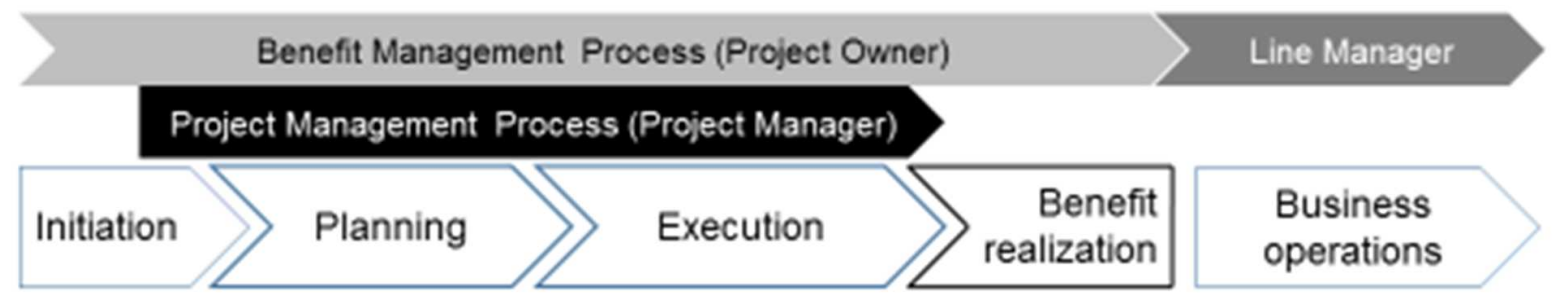

Figure 1. The benefit management and project management processes across project life

Project benefit management is a timely research topic to advance the project management discipline towards a significant impact on business. Projects give effect to strategy and so thinking strategically about projects has the potential to position them as a core value creation activity. Benefit management holds open the prospect of expanding the reach of the project management discipline to top management by shaping projects as instruments of business strategy implementation.

\section{References:}

Breese, R., Jenner, S., Serra, C. E. M., Thorp, J. 2015. Benefits management: Lost or found in translation. International Journal of Project Management, 33, 1438-1451.

Shenhar, A. J., Dvir, D. 2007. Reinventing project management: The diamond approach to successful growth and innovation. Harvard Business School Press: Boston, MA. 
Zwikael, O., Smyrk, J. R. 2012. A general framework for gauging the performance of initiatives to enhance organizational value. British Journal of Management, 23, S6-S22.

Zwikael, O., Smyrk, J. 2015. Project governance: Balancing control and trust in dealing with risk. International Journal of Project Management, 33 (3), 852-862.

\section{Guest Editor}

Ofer Zwikael

Research School of Management

The Australian National University

ofer.zwikael@anu.edu.au 